


\section{climate}

an Open Access Journal by MDPI

Editor-in-Chief

Dr. Timothy G. F. Kittel

Associate Editor

Dr. Nir Y. Krakauer

Section Editors-in-Chief

Dr. Forrest M. Hoffman

Prof. Dr. Salvatore Magazù

Prof. Dr. Rui A. P. Perdigão

\section{Message from the Editor-in-Chief}

Climate (ISSN 2225-1154) was established in 2013 to provide an open-access outlet for innovative research, review articles, new direction papers, and short communications relevant to all disciplines related to climate at all scales. The journal encourages papers ranging from climate change detection and attribution and Earth system modeling, to ecosystem, hydrologic, and socioeconomic impacts and climate mitigation and adaptation measures. The influence of Climate is strong and growing (CiteScore 4.7 in 2021). We welcome your paper submission and proposals for special issues.

\section{Author Benefits}

Open Access Unlimited and free access for readers

C No Copyright Constraints Retain copyright of your work and free use of your article

\section{\& Thorough Peer-Review}

$\circlearrowright$ Rapid Publication First decision provided to authors approximately 13.9 days after submission; acceptance to publication is undertaken in 3.7 days (median values for papers published in this journal in the second half of 2022)

S Discounts on Article Processing Charges (APC) If you belong to an institute that participates with the MDPI Institutional Open Access Program

Coverage by Leading Indexing Services Scopus, ESCI (Web of Science), GeoRef, AGRIS, and other databases

【 No Space Constraints, No Extra Space or Color Charges No restriction on the length of the papers, number of figures or colors

Journal Rank CiteScore-Q2 (Atmospheric Science) 


\section{Aims and Scope}

Climate is an international and open access journal on climate research at all scales. Our aim is to encourage scientists to publish high quality research as quick and much detail as possible.

The scope of Climate includes:

Global, regional, and urban climate and their interplays

Climate dynamics and variability

Impact of climate on short-term extreme events

Chemistry, aerosol, cloud, and climate interactions

Hydroclimate

Interactions of air, land, water, and plant

Interactions of water-, energy-, and carbon-cycles

Impact of climate on air/water quality, ecosystem, human health, food production

Impact of climate on economy and society

Climate mitigation and adaptation policies and strategies

Sustainability, clean energy, and pollution control

Geoengineering

\section{Journal Sections}

- Climate Dynamics and Modelling

- Policy, Governance, and Social Equity

- Climate and Environment

- Climate and Economics

- Climate Adaptation and Mitigation

\section{Editorial Office}

Climate Editorial Office climate@mdpi.com MDPI, St. Alban-Anlage 66 4052 Basel, Switzerland Tel: +41616837734 www.mdpi.com mdpi.com/journal/climate

- Weather, Events and Impacts

- Climate Change and Urban Ecosystems 
GSPA

The Association of
Learned \& Professional
Society Publishers

\section{Crossref}

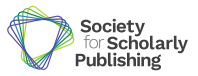

STM'

\section{DOAJ}

SPARC $*$ Europe
$|\mathbf{C}| \mathbf{O}|\mathbf{P}| \mathbf{E}$

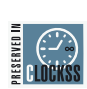

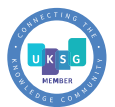

ORCID

\title{
Affiliated Societies
}

\section{AMERICAN SOCIETY OF ADAPTATION PROFESSIONALS}

\section{Follow}

\author{
f facebook.com/MDPIOpenAccessPublishing \\ twitter.com/MDPIOpenAccess \\ in linkedin.com/company/mdpi \\ (O) instagram.com/mdpiopenaccess \\ 6 weibo.com/mdpicn \\ \%.) Wechat: MDPI-China
}

\section{Subscribe}

blog.mdpi.com 